\title{
Behaviour of radionuclides in the presence of superplasticiser
}

\section{Amy J. Young}

Loughborough University, Loughborough, Leicestershire, UK Peter Warwick

Director, Enviras Ltd, Loughborough, Leicestershire, UK

\section{Antoni E. Milodowski}

Principal Petrologist, British Geological Survey, Keyworth, Nottinghamshire, UK

David Read

Professor of Radiochemistry, Loughborough University, Loughborough, Leicestershire, UK

Superplasticisers improve the flow properties of fresh cement and offer undoubted benefits to the construction sector. There is concern in the nuclear industry, however, that the presence of a superplasticiser in grout or backfill cement may increase the solubility of radionuclides in the cementitious pore water and/or reduce their adsorption from solution. This paper describes the effect of a commercial, polycarboxylated, polyether comb type superplasticiser on the behaviour of selected metals in blended cements through a series of batch and monolith leach experiments. Results of batch experiments show that the presence of free superplasticiser in solution reduces uptake of nickel $\left({ }^{63} \mathrm{Ni}\right)$ and europium $\left({ }^{152} \mathrm{Eu}\right)$ by both blast-furnace-slag- and pulverised-fly-ash-modified ordinary Portland cement. Further, metal bound in the presence of free superplasticiser is readily remobilised on exposure to fresh cement solution. Conversely, metal uptake is almost complete and appears irreversible when exposed to hardened cements prepared with superplasticiser as part of the original mix. Monolithic slag cement samples prepared with superplasticiser suffer from bleed, with the surplus water containing a significant proportion of the metals added, including uranium and thorium. Digital autoradiography reveals heterogeneous distribution of radioactivity in the monoliths and demonstrates that the dissolved metals have not been effectively immobilised throughout the specimen. The mobility of thorium may indicate similar behaviour by other tetravalent actinide species, notably Pu(IV) and Np(IV).

\section{Introduction}

A substantial legacy of radioactive waste has accumulated in the UK, much of it arising from civil nuclear power generation over the past 60 years. In the event that new nuclear power plants enter service, as is currently envisaged, waste created by the new facilities will also need to be managed and disposed of safely.

UK government policy states that deep geological disposal, coupled with safe and secure interim storage, is the preferred option for managing the UK's inventory of nuclear waste. Geological disposal is a multi-barrier, multi-phased approach based on placing suitably packaged and contained waste in an underground repository. Interim surface storage provides a secure store for packaged waste throughout the period during which the repository is in the planning, development and licensing stage (Pöyry Energy, 2011).

Concrete and cement will inevitably play an important role in the construction of a geological repository. Standard techniques used for underground construction will be employed and therefore concrete will be used for the walls, floors and ceilings of the vaults, shafts and tunnels. Current repository designs consider immobilisation of intermediate level waste (ILW) and longerlived low-level waste (LLW) in cement-based grout and packaged in standardised stainless steel or concrete-lined, stainless steel containers. The waste packages will then be stored in engineered vaults within the host geological environment. These packages could remain underground until the vault is full, which could take many decades. Subsequently, a decision will be made either to leave the vault open, with the option of retrieving the waste in the future, or to backfill the vault, the shafts and tunnels with cementitious materials in order to support long-term containment and isolation of the wastes.

The cement backfill is designed to provide an important chemical barrier to radionuclide migration: first, by providing a high surface area available for radionuclide uptake and second, by chemically conditioning the cement pore water to high $\mathrm{pH}$ (Glasser, 2001). The presence of portlandite $\left(\mathrm{Ca}(\mathrm{OH})_{2}\right)$, with a solubility of $\sim 1 \mathrm{~g} /$ $\mathrm{dm}^{3}$ at $25^{\circ} \mathrm{C}$, buffers the cement pore water to $\mathrm{pH} 12 \cdot 5$, conditions under which actinides such as uranium, plutonium and americium tend to display low solubility. Uptake of radionuclides by cements may also retard migration by way of ion exchange and adsorption on, or incorporation in, mineral phases.

It is important to understand the implications of using cementbased materials in the construction of a repository. Many types of cement matrix exist, with the partial substitution of pozzolans - 
such as pulverised fly ash (PFA), or latent hydraulic materials, for example, blast furnace slag (BFS) - for ordinary Portland cement (OPC). Additives, primarily retarders and superplasticisers, may present specific benefits to the nuclear industry in terms of formulation envelopes and workability, but they also introduce uncertainty regarding the potential fate of radioactive species.

Superplasticisers belong to a group of cement additives known as high-range water reducers. They are polymeric molecules and are widely used in the construction industry to improve flow characteristics while reducing the water content of a cement formulation by around $30 \%$, providing higher compressive strength (Ramachandran, 1995; Yamada et al., 2000). Superplasticisers are synthetic chemicals consisting of high-molecular-weight, water-soluble organic polymers. Solubility is ensured by the presence of adequate hydroxyl, sulfonate or carboxylate groups attached to the main organic repeat unit, which is usually anionic in nature (Hewlett, 1998).

Many organic molecules, for example ethylenediaminetetraacetic acid (EDTA), used as a decontamination agent in radioactive waste streams, are able to complex radionuclides (Cetiner, 2007; Felmy and Qafoku, 2004; Warwick et al., 2008). Some superplasticisers (sulfonated melamine formaldehyde and sulfonated naphthalene formaldehyde) have also been shown to increase the solubility of radionuclides, including U(VI) and $\mathrm{Pu}(\mathrm{IV})$, in high$\mathrm{pH}$ solutions representative of cement-conditioned pore water (Greenfield et al., 1998; McCrohon and Williams, 1997). Owing to this potential uncertainty, their use in a geological repository in the UK has not been considered. More recently, highly effective superplasticisers based on polycarboxylated polyether comb polymers have been developed. Little is yet known of their complexation with radionuclides or their impact on radionuclide solubility and adsorption. Such information is a prerequisite when considering whether this type of polymer could be used in the context of a repository. The current paper focuses on one such polycarboxylated superplasticiser, ADVA Cast 551, the structure of which is shown in Figure 1.

The behaviour of selected radioactive metals in two grouts is compared in the presence and absence of superplasticiser

(a) by regarding the superplasticiser as a 'ligand' where batch experiments of metal uptake on crushed cement are carried out with increasing concentrations of free superplasticiser in solution

(b) by investigating metal uptake in cements prepared with superplasticiser already present; the subsequent leaching of metal from hardened cements prepared with and without superplasticiser is then assessed.

The objectives above also impact on the ability of superplasticiser-modified cement to act as a grout because reactions immediately after water addition can have a major bearing on subsequent performance (Petit et al., 2005; Schlegel et al., 2012).



Figure 1. Comb-type polycarboxylate superplasticiser, ADVA Cast 551

\section{Experimental work}

Two cement formulations were investigated: BFS:OPC (9:1) and PFA:OPC (3:1). The BFS (BNFL Specification 7th revision) was supplied by Civil and Marine. The PFA (Class S, Category B, manufactured to comply with the requirements of BS EN450 FA: 2005 to BNFL specification 6th revision) was supplied by Cemex. The OPC used (BNFL specification 7th revision, manufactured to comply with the requirements of BS EN 197-1:2000 type CEM I, Portland Cement Strength Class 42, 5N) was supplied by Castle Cement.

The following metal salts were used in the experiments - uranyl nitrate $\left(\mathrm{UO}_{2}\left(\mathrm{NO}_{3}\right)_{2}\right)$ (BDH Laboratory Reagents), nickel nitrate $\left(\mathrm{Ni}\left(\mathrm{NO}_{3}\right)_{2}\right)$ (Sigma Aldrich), europium (III) chloride $\left(\mathrm{EuCl}_{3}\right)$ (Acros Organics) and thorium nitrate $\left(\mathrm{Th}\left(\mathrm{NO}_{3}\right)_{4}\right)$ (Fluka). In the metal uptake experiments, radioactive spikes of nickel and europium were used in the form of ${ }^{63} \mathrm{Ni}$ and ${ }^{152} \mathrm{Eu}$, respectively (both supplied by Eckert and Ziegler). ADVA Cast 551 was supplied by Grace Construction Products.

\section{Effect of free ADVA Cast 551 on nickel and europium uptake by crushed cements}

The cement powders (BFS:OPC and PFA:OPC without superplasticiser) were weighed into a plastic beaker according to the compositions shown in Table 1 and mixed thoroughly. Water was added slowly over 2 min with stirring. The mix was stirred for a further 4 min before pouring into a plastic mould (Morgan and Constable, 2008), covered with parafilm and left for $24 \mathrm{~h}$ before demoulding. The specimens were then cured at $>90 \%$ humidity for $28 \mathrm{~d}$. After curing, the samples were allowed to dry for $24 \mathrm{~h}$, then crushed, sieved and the $<180 \mu \mathrm{m}$ fraction used for the experiments. $0 \cdot 5 \mathrm{~g}$ of solid was weighed into plastic vials. 


\section{Offprint provided courtesy of www.icevirtuallibrary.com} Author copy for personal use, not for distribution

\begin{tabular}{lccccc}
\hline Sample & Water: $g$ & BFS: $g$ & PFA: $g$ & OPC: $g$ & W/s \\
\hline BFS:OPC & 52.92 & 132.3 & 0 & 14.7 & 0.36 \\
PFA:OPC & 52.92 & 0 & 110.25 & 36.75 & 0.36
\end{tabular}

Table 1. Cement formulations (prepared without superplasticiser)

w/s - water:solid ratio

Solutions of nickel nitrate and europium (III) chloride were prepared at a concentration of $10^{-9} \mathrm{~mol} / \mathrm{dm}^{3}$ using the appropriate cement-conditioned water. This concentration was chosen to be lower than the estimated solubility limit for each metal hydroxide at high $\mathrm{pH}\left(6 \times 10^{-8} \mathrm{~mol} / \mathrm{dm}^{3}\right.$ for $\mathrm{Ni}$ (Felmy and Qafoku, 2004) and $6 \times 10^{-7} \mathrm{~mol} / \mathrm{dm}^{3}$ for Eu (Aldridge, 2005). A spike of either ${ }^{63} \mathrm{Ni}$ or ${ }^{152} \mathrm{Eu}$ was added to bring the activity of each sample to $3 \mathrm{kBq}$. ADVA Cast 551 was added in solution at $0,0 \cdot 2,0 \cdot 5$ and $1 \%$ (weight/volume $(\mathrm{w} / \mathrm{v})$ ), respectively to assess the effect of increasing concentration of superplasticiser on the uptake of the metals by the cement. The samples were allowed to equilibrate on a flat-bed shaker for $28 \mathrm{~d}$. The liquid to solid ratio was $40: 1$ (i.e. $20 \mathrm{~cm}^{3}$ of solution in contact with $0.5 \mathrm{~g}$ solid).

Desorption experiments were carried out to investigate the reversibility of metal uptake when superplasticiser was present in solution. All of the supernatant was removed from the cement solid and $10 \mathrm{~cm}^{3}$ of fresh cement equilibrated water added. The samples were then shaken on a flat-bed shaker for a further $28 \mathrm{~d}$.

\section{Uptake of nickel and europium by superplasticiser-} modified cements

In these experiments, uptake of metals was measured onto crushed BFS:OPC and PFA:OPC that had been prepared with ADVA Cast $551(0 \cdot 5 \%(\mathrm{w} / \mathrm{s})$ superplasticiser) present as part of the original formulation. The cements were cured and crushed prior to the experiments as described above and $0.5 \mathrm{~g}$ weighed into plastic vials. Compositional data are given in Table 2.

Nickel and europium solutions at a concentration of $10^{-9} \mathrm{~mol} / \mathrm{dm}^{3}$ were prepared as above in the relevant cement-conditioned water and $10 \mathrm{~cm}^{3}$ solution added to the weighed cement solid. The samples were allowed to equilibrate on a flat-bed shaker for $28 \mathrm{~d}$.

The reversibility of metal uptake was investigated by conducting a desorption experiment similar to that described above. All the supernatant was removed from the cement solids and $10 \mathrm{~cm}^{3}$ of fresh cement equilibrated solution added before equilibration on a flatbed shaker for a further $28 \mathrm{~d}$.

\section{Leaching of nickel, uranium and thorium from cement} monoliths prepared with and without superplasticiser The leaching behaviour of U(VI), Th and Ni from BFS:OPC and PFA:OPC, prepared with and without the addition of $0.5 \%(\mathrm{w} / \mathrm{s})$ superplasticiser, was also investigated using monolithic samples. These were prepared by adding uranyl nitrate, thorium nitrate and nickel nitrate respectively to the water of each cement mix to give a loading of $200 \mathrm{ppm}$ (weight for weight (w/w)). The metal nitrates are soluble in water at near neutral $\mathrm{pH}$; therefore, adding them before mixing with the cement powders should result in homogeneous monoliths. The composition of the cement monoliths is given in Table 3.

The design of the leaching experiment was based on the 'tank leach test' as described by Conner (1990) and Takahashi et al. (2007). The extent of metal leaching is dependent on fixation of the elements by amorphous and microcrystalline phases (largely calcium silicate hydrate, $\mathrm{C}-\mathrm{S}-\mathrm{H}$ ) produced during the hydration of the cement, the formation of metal hydroxides at high $\mathrm{pH}$ and metal diffusion. Cement prepared with superplasticiser has a lower porosity; therefore, a decrease in metal diffusion attributable to a reduced pore volume may be expected.

After mixing, the cements were poured into plastic moulds, covered with parafilm, and allowed to cure for $48 \mathrm{~h}$. After this time, the samples were demoulded and the ends of each block sealed with paraffin wax. The blocks were then submerged in a known volume of the appropriate conditioned water (either BFS:OPC or PFA:OPC) and sealed in screw-top Pyrex jars. The cylindrical samples were $5 \mathrm{~cm}$ long with diameter of $2 \mathrm{~cm}$, giving a volume ratio of block to leachate of approximately $2: 1$. The samples were left for 4 months before aliquots of the leachate solution were removed for analysis.

\begin{tabular}{lccccccc}
\hline Sample & Water: & \% SP & ADVA Cast 551: & BFS: & PFA: & OPC: $g$ & W/s \\
\hline BFS:OPC & 51.92 & 0.5 & 1 & 132.3 & 0 & 14.7 & 0.36 \\
PFA:OPC & 51.92 & 0.5 & 1 & 0 & 110.25 & 36.75
\end{tabular}

Table 2. Cement formulations (prepared with superplasticiser, 


\begin{tabular}{|c|c|c|c|c|c|c|c|}
\hline Sample & OPC: $g$ & BFS: $g$ & PFA: $g$ & $\mathrm{w} / \mathrm{s}$ ratio & $\mathrm{UO}_{2}\left(\mathrm{NO}_{3}\right)_{2}: \mathrm{g}$ & $\mathrm{Th}\left(\mathrm{NO}_{3}\right)_{4}: \mathrm{g}$ & $\mathrm{Ni}\left(\mathrm{NO}_{3}\right)_{2}: \mathrm{g}$ \\
\hline $\begin{array}{l}\text { BFS:OPC } \\
\text { No SP }\end{array}$ & $14 \cdot 7$ & $132 \cdot 3$ & - & 0.36 & - & - & - \\
\hline $\begin{array}{l}\text { BFS:OPC } \\
\text { No SP - U }\end{array}$ & $14 \cdot 7$ & $132 \cdot 3$ & - & $0 \cdot 36$ & 0.7 & - & - \\
\hline $\begin{array}{l}\text { BFS:OPC } \\
\text { No SP - Th }\end{array}$ & $14 \cdot 7$ & $132 \cdot 3$ & - & 0.36 & - & 0.08 & - \\
\hline $\begin{array}{l}\text { BFS:OPC } \\
\text { No SP - Ni }\end{array}$ & $14 \cdot 7$ & $132 \cdot 3$ & - & 0.36 & - & - & $0 \cdot 14$ \\
\hline $\begin{array}{l}\text { BFS:OPC } \\
0.5 \% \text { SP }\end{array}$ & 14.7 & $132 \cdot 3$ & - & 0.36 & - & - & - \\
\hline $\begin{array}{l}\text { BFS:OPC } \\
0.5 \% \text { SP - U }\end{array}$ & 14.7 & $132 \cdot 3$ & - & 0.36 & 0.7 & - & - \\
\hline $\begin{array}{l}\text { BFS:OPC } \\
0.5 \% \text { SP - Th }\end{array}$ & $14 \cdot 7$ & $132 \cdot 3$ & - & 0.36 & - & 0.08 & - \\
\hline $\begin{array}{l}\text { BFS:OPC } \\
0.5 \% \text { SP Ni }\end{array}$ & 14.7 & $132 \cdot 3$ & - & 0.36 & - & - & $0 \cdot 14$ \\
\hline $\begin{array}{l}\text { PFA:OPC } \\
\text { No SP }\end{array}$ & $36 \cdot 75$ & - & $110 \cdot 25$ & 0.36 & - & - & - \\
\hline $\begin{array}{l}\text { PFA:OPC } \\
\text { No SP - U }\end{array}$ & 36.75 & - & $110 \cdot 25$ & 0.36 & 0.7 & - & - \\
\hline $\begin{array}{l}\text { PFA:OPC } \\
\text { No SP - Th }\end{array}$ & 36.75 & - & $110 \cdot 25$ & 0.36 & - & 0.08 & - \\
\hline $\begin{array}{l}\text { PFA:OPC } \\
\text { No SP - Ni }\end{array}$ & 36.75 & - & $110 \cdot 25$ & 0.36 & - & - & 0.14 \\
\hline $\begin{array}{l}\text { PFA:OPC } \\
0.5 \% \text { SP }\end{array}$ & $36 \cdot 75$ & - & $110 \cdot 25$ & 0.36 & - & - & - \\
\hline $\begin{array}{l}\text { PFA:OPC } \\
0.5 \% \text { SP }-U\end{array}$ & $36 \cdot 75$ & - & $110 \cdot 25$ & 0.36 & 0.7 & - & - \\
\hline $\begin{array}{l}\text { PFA:OPC } \\
0.5 \% \text { SP - Th }\end{array}$ & $36 \cdot 75$ & - & $110 \cdot 25$ & 0.36 & - & 0.08 & - \\
\hline $\begin{array}{l}\text { PFA:OPC } \\
0.5 \% \mathrm{SP}-\mathrm{Ni}\end{array}$ & $36 \cdot 75$ & - & $110 \cdot 25$ & 0.36 & - & - & $0 \cdot 14$ \\
\hline
\end{tabular}

Table 3. Formulations for leaching experiments on cement monoliths

In the case of the BFS:OPC samples, bleed water was present on the surface after the $48 \mathrm{~h}$ set time, particularly in those samples that contained superplasticiser. The water was collected and analysed for the metals of interest by inductively coupled plasma mass spectrometry (ICP-MS). The quantity of metal leached in the bleed water was taken into account in the calculations.

Aliquots of the supernatant were removed from the samples and analysed for the metals of interest after filtering through a $0.45 \mu \mathrm{m}$ filter. Nickel $\left({ }^{63} \mathrm{Ni}\right)$ was analysed by liquid scintillation counting (LSC) using a Tri-Carb 2750 TR/LL Packard liquid scintillation counter. $1 \mathrm{~cm}^{3}$ of supernatant was added to $10 \mathrm{~cm}^{3}$ of GoldStar LSC cocktail (Meridian), the samples shaken on a whirl-mixer and allowed to settle for $1 \mathrm{~h}$ before counting. Europium $\left({ }^{152} \mathrm{Eu}\right)$ samples were analysed by gamma counting using a Cobra II auto gamma spectrometer (Packard). Uranium was measured by ICP-MS using a 7700x series quadrupole ICP-MS (Agilent Technologies). The supernatant was acidified with $0.5 \%$ analytical grade nitric acid $\left(\mathrm{HNO}_{3}\right)$ before analysis. The ICP-MS instrument was calibrated on a daily basis using a uranium standard solution (Fisher). Sample vials were washed three times with $0.5 \%$ nitric acid to check for adsorption to the vial; no loss of metal to the vessel walls was observed.

The homogeneity of the cement monoliths was assessed by scanning electron microscopy (field emission gun SEM) in the case of nickel, and digital autoradiography in the case of uranium and thorium (Amemiya and Miyahara, 1988). The blocks for SEM analysis were removed from the leachate solutions and cut axially using a diamond circular blade saw to produce a cross-sectional sample. Wet/dry sand paper was used to smooth the cut surfaces, which were then sputter coated with gold before analysis. For 
autoradiography, the planar cut surfaces of the cement blocks were placed on to $\mathrm{Eu}^{2+}$-doped $\mathrm{BaFBr}$ storage phosphor autoradiography plates (Fuji BAS MS-type polyurethane-coated, general-purpose plates) and sealed in a light-tight box. The uranium- and thoriumcontaining blocks were exposed for 7 and $14 \mathrm{~d}$, respectively, and the images were recorded by scanning the imaging plates with red laser light $(635 \mathrm{~nm})$ to release the stored energy, induced in the phosphor as photostimulated luminescence (PSL) (Gonzalez et al., 2002; Zeissler, 1997). Laser scanning and recording of the PSL signal was carried out using an Amersham Biosciences (GE Healthcare Ltd) Storm 860 digital autoradiograph and fluorescence scanner. The storage phosphor plates were scanned at a $50 \mu \mathrm{m}$ pixel resolution and the digital autoradiograph images obtained were processed using the ImageQuant TL (version 2005, Amersham Biosciences) and ImageJ (version 1.38x) software packages operating on a Windows XP personal computer workstation.

\section{Results}

Effect of free ADVA Cast 551 on nickel and europium uptake by crushed cements

The uptake of nickel onto BFS:OPC grout as a function of free superplasticiser in solution is shown in Figure 2. In the absence of ADVA Cast 551, uptake is effectively complete but decreases linearly with increasing concentration of ADVA Cast 551 such that, at $1 \%$ superplasticiser, less than $30 \%$ of the nickel inventory is bound. The effect is reversible, although there is discernible hysteresis (Figure 2). With no superplasticiser present, $<1 \%$ of the nickel bound is re-suspended, but the addition of even a small amount $(0 \cdot 2 \%)$ of ADVA Cast 551 has a marked impact on the ability of the cement to retain the metal. In the solutions containing $\geqslant 0.5 \%$ ADVA Cast 551 , more than $98 \%$ of the bound nickel was re-suspended.

Nickel uptake onto PFA:OPC grout displays similar trends (Figure 3). However, in comparison to BFS:OPC, more metal is bound and less released at corresponding concentrations of

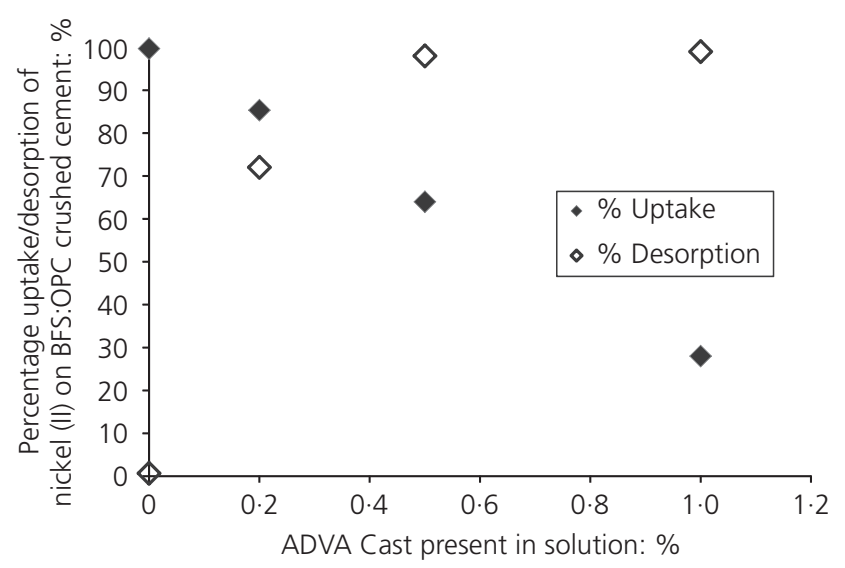

Figure 2. Uptake of nickel to, and release from, crushed BFS:OPC grout with free ADVA Cast 551 in solution

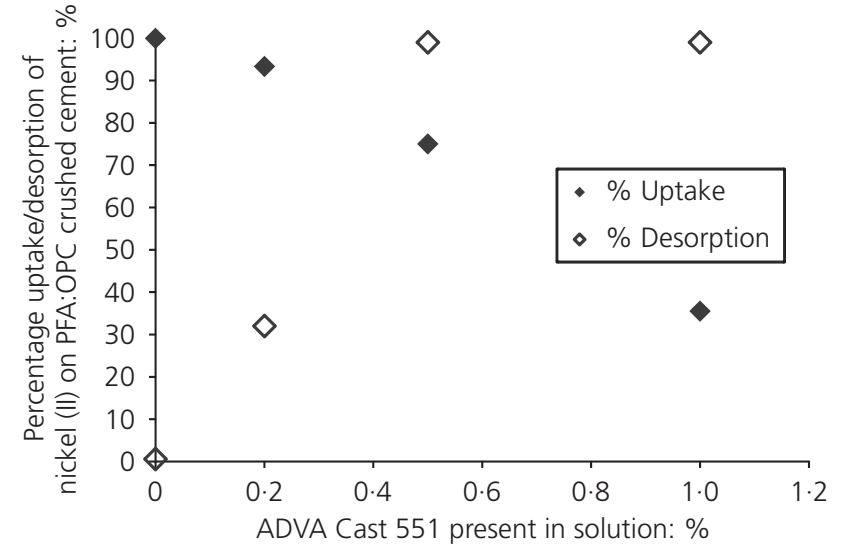

Figure 3. Uptake of nickel to, and release from, crushed PFA:OPC grout with free ADVA Cast 551 in solution

ADVA Cast 551. The differences are most marked at $0 \cdot 2 \%$ superplasticiser (a typical commercial dosage), where the reduction in nickel uptake is only 5\%. Again, at higher concentrations of superplasticiser more than $99 \%$ of the bound metal was resuspended when exposed to fresh cement solution.

The percentage uptake of europium onto crushed BFS:OPC and PFA:OPC is shown in Figures 4 and 5, respectively. The behaviour of trivalent europium broadly follows that of nickel, although some trends are more pronounced. The proportion of metal bound is sharply reduced by superplasticiser even at low concentrations; only $0 \cdot 2 \%$ ADVA Cast 551 is sufficient to reduce europium uptake by half for both cement formulations. Thereafter, the slag samples show little change, with uptake stabilising at around $40 \%$ of the metal added. In contrast, proportional uptake continues to decrease with PFA:OPC grout, reaching 20\% with $1 \%$ superplasticiser present in solution. Differences in desorption behaviour are also apparent. More than $97 \%$ of the metal was resuspended during the desorption experiment on BFS:OPC at all

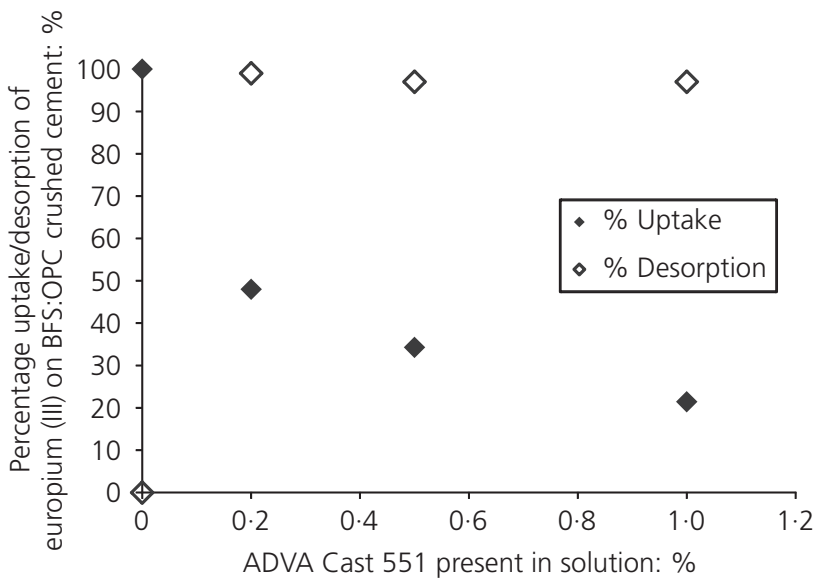

Figure 4. Uptake of europium to, and release from, crushed BFS:OPC grout with free ADVA Cast 551 in solution 


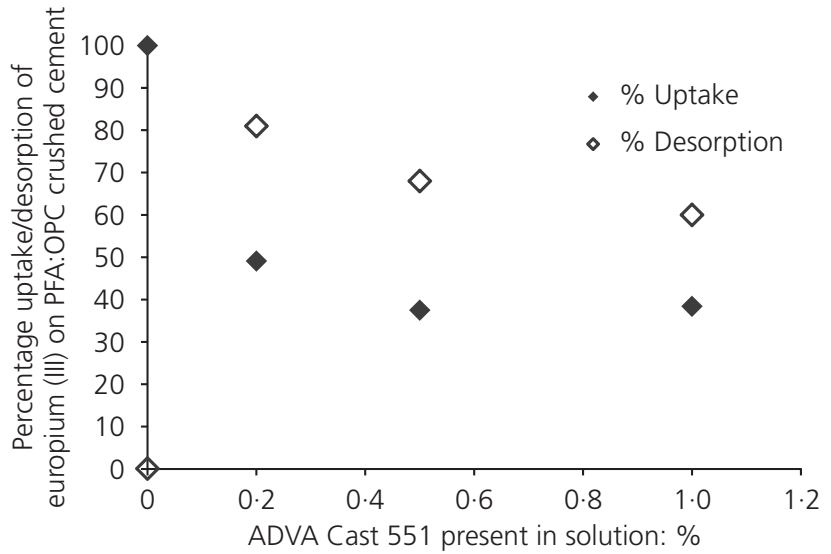

Figure 5. Uptake of europium to, and release from, crushed PFA:OPC grout with free ADVA Cast 551 in solution

concentrations of ADVA Cast (Figure 4). In contrast, desorption of europium from the fly ash grout reaches a peak at $0 \cdot 2 \%$ superplasticiser (Figure 5), implying that a fraction of the metal is irreversibly bound, at least on the timescale of the experiment.

\section{Uptake of nickel and europium by crushed cements} prepared with superplasticiser

Uptake of nickel and europium to crushed cements prepared with $0.5 \%$ superplasticiser is shown in Table 4. Nickel uptake is $98 \%$ for both the slag and fly ash grouts. Europium uptake is even greater $(>99 \%)$ as levels in the residual solution were below detection. These data demonstrate that ADVA Cast 551 does not affect uptake of the metals when already incorporated in the grout, in marked contrast to when the superplasticiser is free in solution. Desorption was also investigated (Table 5). The results show that $(<1 \%)$ is re-suspended in each case.

Leaching of nickel, uranium and thorium from cement monoliths prepared with and without superplasticiser Results for leaching of nickel, uranium (VI) (U(VI)) and thorium from BFS:OPC are shown in Table 6. As noted previously, bleed water was found on the BFS:OPC cement blocks; however, there was substantially greater bleed in the samples containing ADVA Cast 551. This water was collected and analysed by ICP-MS. It is apparent that a significant proportion of the metals added are present in the bleed above the cement prepared with superplasticiser. In the case of uranium, $32 \%$ of the original inventory was found in the bleed water, the corresponding values for thorium and nickel are $26 \%$ and $19 \%$, respectively. In the case of slag cement prepared without superplasticiser, less than $1 \%$ of the original metal inventory was found in the bleed (Table 6). No bleed was associated with the PFA:OPC cement on setting.

On subsequent leaching, the concentrations of uranium and thorium released from the BFS:OPC monoliths were very low (Table 6). With nickel, a similar concentration of metal (within a factor of 2) was leached from the cement irrespective of whether the block contained superplasticiser. Therefore, short-term behaviour in the form of bleed appears to have little impact on longer term trends, in this case leaching over a period of 4 months.

\begin{tabular}{|c|c|c|c|}
\hline Sample & [Ni] bound: $\mathrm{mol} / \mathrm{dm}^{3}$ & [Ni] solution: $\mathrm{mol} / \mathrm{dm}^{3}$ & $\%$ Upta \\
\hline BFS:OPC (0.5\% SP) & $2 \cdot 7 \times 10^{-9}$ & $6.8 \times 10^{-11}$ & 98 \\
\hline \multirow[t]{2}{*}{ PFA:OPC (0.5\% SP) } & $2.6 \times 10^{-9}$ & $2.5 \times 10^{-10}$ & 98 \\
\hline & [Eu] bound: $\mathrm{mol} / \mathrm{dm}^{3}$ & [Eu] solution: $\mathrm{mol} / \mathrm{dm}^{3}$ & \\
\hline BFS:OPC (0.5\% SP) & $3.84 \times 10^{-10}$ & $<\mathrm{LOD}$ & $>99$ \\
\hline PFA:OPC (0.5\% SP) & $3.70 \times 10^{-10}$ & $<\mathrm{LOD}$ & $>99$ \\
\hline
\end{tabular}

Table 4. Uptake of nickel and europium by crushed grouts prepared with $0.5 \%$ ADVA Cast 551

\begin{tabular}{lccc}
\hline Sample & [Ni] originally bound: $\mathrm{mol} / \mathrm{dm}^{3}$ & [Ni] desorbed: $\mathrm{mol} / \mathrm{dm}^{3}$ & Percentage desorption: \% \\
\hline BFS:OPC (0.5\% SP) & $2.66 \times 10^{-9}$ & $6.73 \times 10^{-13}$ & 0.03 \\
PFA:OPC (0.5\% SP) & $2.65 \times 10^{-9}$ & $7.68 \times 10^{-13}$ & 0.03 \\
& {$\left[\right.$ Eu] originally bound: $\mathrm{mol} / \mathrm{dm}^{3}$} & {$\left[\right.$ Eu] desorbed: $\mathrm{mol} / \mathrm{dm}^{3}$} & 0.3 \\
BFS:OPC (0.5\% SP) & $3.84 \times 10^{-10}$ & $1.14 \times 10^{-12}$ & 0.2 \\
PFA:OPC (0.5\% SP) & $3.70 \times 10^{-10}$ & $7.48 \times 10^{-13}$ &
\end{tabular}

Table 5. Nickel and europium desorption from crushed grouts prepared with 0.5\% ADVA Cast 551 


\begin{tabular}{|c|c|c|c|c|c|c|}
\hline Sample & $\begin{array}{c}\text { Metal added: } \\
\mathrm{mol} / \mathrm{dm}^{3}\end{array}$ & $\begin{array}{c}\text { Metal in bleed } \\
\text { water }\end{array}$ & $\begin{array}{c}\text { Percentage in } \\
\text { bleed: \% }\end{array}$ & $\begin{array}{l}\text { Metal in block: } \\
\mathrm{mol} / \mathrm{dm}^{3}\end{array}$ & $\begin{array}{l}\text { Metal leached: } \\
\mathrm{mol} / \mathrm{dm}^{3}\end{array}$ & $\begin{array}{l}\text { Percentage } \\
\text { leached: \% }\end{array}$ \\
\hline Ni No SP & $1.47 \times 10^{-2}$ & $<\mathrm{LOD}^{\mathrm{a}}$ & $<0.0001$ & 0.015 & $5 \cdot 16 \times 10^{-7}$ & 0.004 \\
\hline $\mathrm{Ni} 0.5 \% \mathrm{SP}$ & $1.52 \times 10^{-2}$ & $2.85 \times 10^{-3}$ & 19 & $1.23 \times 10^{-2}$ & $2.34 \times 10^{-7}$ & 0.002 \\
\hline U No SP & $3.36 \times 10^{-2}$ & $1.21 \times 10^{-6}$ & 0.004 & $3.36 \times 10^{-2}$ & $<\mathrm{LOD}^{\mathrm{a}}$ & $<0.0001$ \\
\hline U 0.5\% SP & $3.49 \times 10^{-2}$ & $1.12 \times 10^{-2}$ & 32 & $2.37 \times 10^{-2}$ & $<\mathrm{LOD}^{\mathrm{a}}$ & $<0.0001$ \\
\hline Th No SP & $3.39 \times 10^{-3}$ & $8.07 \times 10^{-8}$ & 0.002 & $3.39 \times 10^{-3}$ & $<\mathrm{LOD}^{\mathrm{a}}$ & $<0.0001$ \\
\hline Th $0.5 \%$ SP & $3.53 \times 10^{-3}$ & $9.15 \times 10^{-4}$ & 26 & $2.62 \times 10^{-3}$ & $<\mathrm{LOD}^{\mathrm{a}}$ & $<0.0001$ \\
\hline
\end{tabular}

a Limit of detection (LOD) values for uranium, thorium and nickel are $8 \times 10^{-9} \mathrm{~mol} / \mathrm{dm}^{3}, 4 \times 10^{-9} \mathrm{~mol} / \mathrm{dm}^{3}$ and $6 \times 10^{-8} \mathrm{~mol} / \mathrm{dm}^{3}$, respectively.

Table 6. Leaching of nickel, uranium and thorium from BFS:OPC monoliths

Leaching of the same metals from the PFA:OPC blend is shown in Table 7. As for the slag samples, no thorium was leached from the blocks prepared with or without superplasticiser. In the case of nickel, approximately $15 \times$ more metal was leached from the blocks that contained superplasticiser, suggesting that it may have enhanced metal release. Nevertheless, absolute concentrations are still lower than those for BFS:OPC (Table 6) and the fractional release is very small. A small amount of uranium was detected in the fly ash tests (Table 7). Slightly more metal is released in the presence of ADVA Cast, in this case by a factor of 2.5 , but at such low concentrations the difference is unlikely to be significant.

The distribution of uranium and thorium in the cement blocks was investigated using digital autoradiography. Figure 6 compares autoradiographic images and depth profile plots of uranium distribution in BFS:OPC cement made with and without superplasticiser $(0 \cdot 5 \%$ ADVA Cast 551). The exposure time was

\begin{tabular}{|c|c|c|c|}
\hline Sample & $\begin{array}{l}\text { Metal added: } \\
\mathrm{mol} / \mathrm{dm}^{3}\end{array}$ & $\begin{array}{l}\text { Metal leached: } \\
\mathrm{mol} / \mathrm{dm}^{3}\end{array}$ & Leach: \% \\
\hline Ni No SP & $1.47 \times 10^{-2}$ & $1.80 \times 10^{-9}$ & 0.000012 \\
\hline $\mathrm{Ni} 0.5 \% \mathrm{SP}$ & $1.48 \times 10^{-2}$ & $2.71 \times 10^{-8}$ & 0.00018 \\
\hline U No SP & $3.43 \times 10^{-2}$ & $2.59 \times 10^{-7}$ & 0.00076 \\
\hline U $0.5 \%$ SP & $3.45 \times 10^{-2}$ & $6.42 \times 10^{-7}$ & 0.0019 \\
\hline Th No SP & $3.31 \times 10^{-3}$ & $<\mathrm{LOD}^{\mathrm{a}}$ & $<0.0000001$ \\
\hline Th $0.5 \%$ SP & $3.53 \times 10^{-3}$ & $<\mathrm{LOD}^{\mathrm{a}}$ & $<0.0000001$ \\
\hline
\end{tabular}

a $L O D$ for thorium is $4 \times 10^{-9} \mathrm{~mol} / \mathrm{dm}^{3}$.

Table 7. Leaching of nickel, uranium and thorium from PFA:OPC monoliths
1 week and darker areas represent regions of higher radioactivity. The uranium distribution in the sample prepared with superplasticiser is concentrated in the first $5 \mathrm{~mm}$ of the block (Figures 6(a) and 6(b)); in other words, the zone that was in contact with uranium-rich bleed water during setting. The remainder of the block contains relatively little uranium. In the absence of superplasticiser, the distribution of activity is homogeneous throughout the sample (Figures 6(c) and 6(d)). The latter demonstrates that the samples were mixed sufficiently prior to moulding.

Similar findings were obtained with thorium (Figure 7). The exposure time was increased to 2 weeks owing to the lower activity of ${ }^{232} \mathrm{Th}$. Image resolution is poorer but, nevertheless, an area of higher radioactivity is discernible in the region where thorium was detected in the bleed water from superplasticisermodified BFS:OPC (Figures 7(a) and 7(b)). The distribution of radioactivity throughout the sample is again homogeneous in the cement prepared without ADVA Cast (Figures 7(c) and 7(d)).

Unlike the BFS:OPC samples, there was no bleed water associated with the PFA:OPC cements, implying that all of the water added, containing both superplasticiser and the metal, was incorporated into the monoliths during the setting time. There is also very little difference in autoradiographic images for uranium (Figure 8) and thorium (Figure 9), irrespective of the presence of superplasticiser (0.5\% ADVA Cast 551).

Stable nickel was used in preparing the cement monoliths and so recourse was made to SEM-energy-dispersive X-ray analysis (SEM-EDX) in an attempt to identify areas of enhanced accumulation. Nickel concentrations in the samples were found to be below the detection limit of the instrument and so no firm conclusions concerning the distribution of this metal can be drawn. However, it is noted that nickel was detected in bleed water from BFS:OPC monoliths prepared with ADVA Cast 551 (Table 6). 

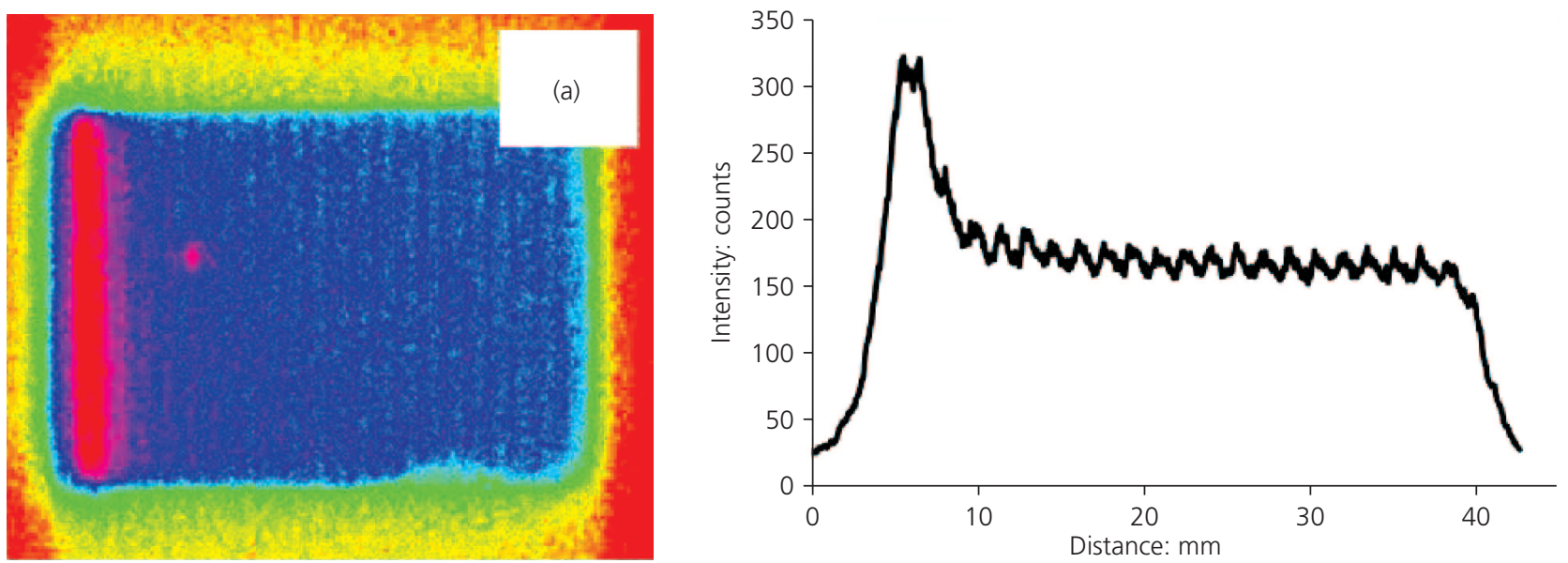

(b)
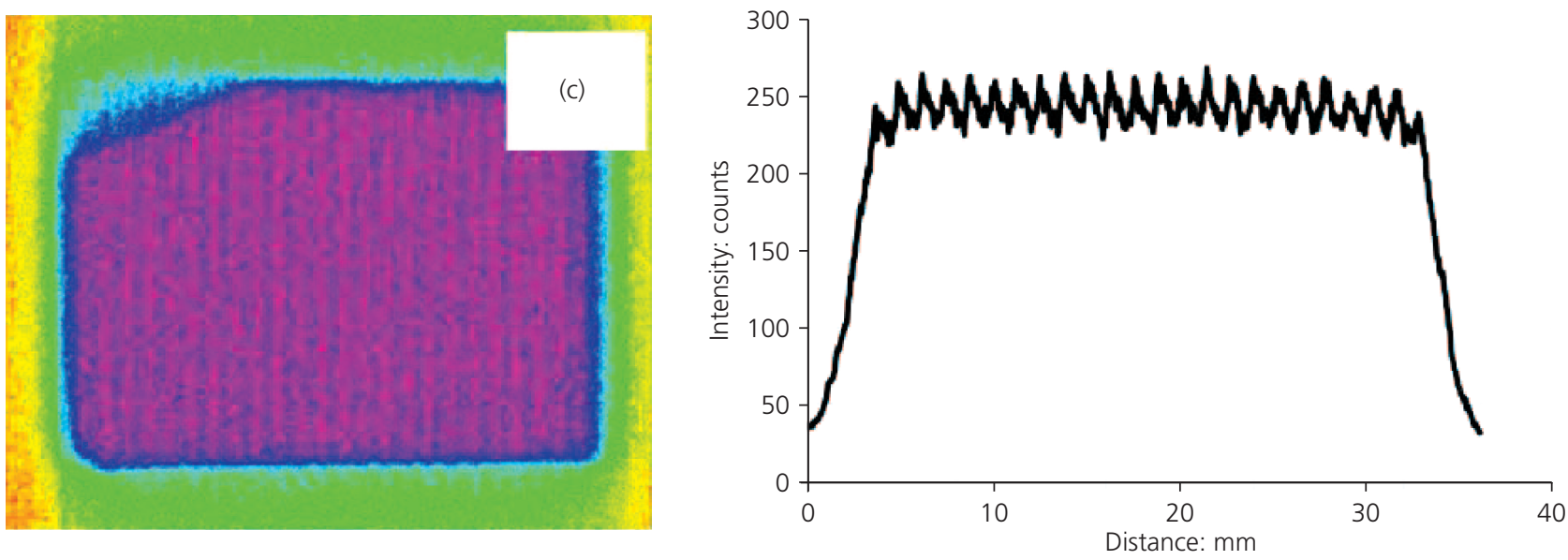

(d)

Figure 6. Autoradiographic image and profile plot of BFS:OPC cement containing uranium prepared (a), (b) with and (c), (d) without 0.5\% ADVA Cast 551

\section{Discussion}

These results show the extent to which a commercial superplasticiser, in this case ADVA Cast 551, can inhibit the uptake of metals onto cured grouts or the incorporation of dissolved metals by cements during curing. They also illustrate that fixing the superplasticiser within the cured grouts reduces its effect on radionuclide behaviour. The findings are significant because uptake by cement is one of the key engineered barriers to radionuclide migration in the design of a repository.

In the absence of superplasticiser, binding of nickel(II) and europium(III) is effectively complete and irreversible (at the same $\mathrm{pH})$. Schlegel et al. (2004) suggest that europium uptake by $\mathrm{C}-\mathrm{S}-\mathrm{H}$ may be explained by substitution for calcium within the structure, owing to their similar ionic radii in seven-fold coordination (1.01 and 1.06 $\AA$, respectively (Shannon, 1976)). As the gel crystallises, the trace metal becomes trapped within the lattice. However, free superplasticiser in solution substantially reduces uptake by both BFS:OPC and PFA:OPC blends. Moreover, when exposed to fresh cement water, the metals are labile and easily re-suspended. Almost all of the bound metals were recovered from BFS:OPC cement when $\geqslant 0.5 \%$ superplasticiser was present in the original solution. Factors thought to be responsible include formation of mixed complexes between the superplasticiser and the metal resulting in increased solubility of the metal (McCrohon and Williams, 1997) and binding of the polymer itself onto the cement surface, thereby blocking sites that are normally available to the metals (Schlegel et al., 2012). In these experiments, trivalent europium is affected more than nickel, displaying $\geqslant 50 \%$ reduction in uptake onto crushed cement, even at low concentrations of superplasticiser $(0 \cdot 2 \%)$. Therefore, enhanced solubility is likely to play at least some part.

Very different results are obtained when metal uptake experi- 

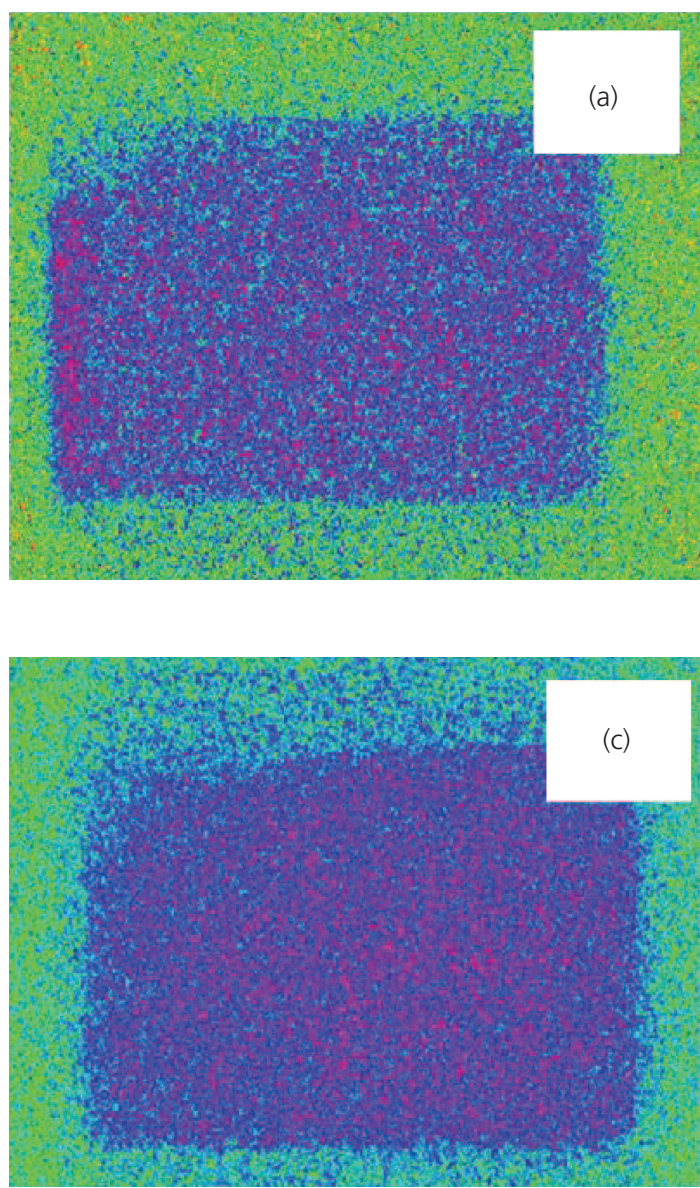

Figure 7. Autoradiographic image and profile plot of BFS:OPC cement containing thorium prepared (a), (b) with and (c), (d) without $0.5 \%$ ADVA Cast 551

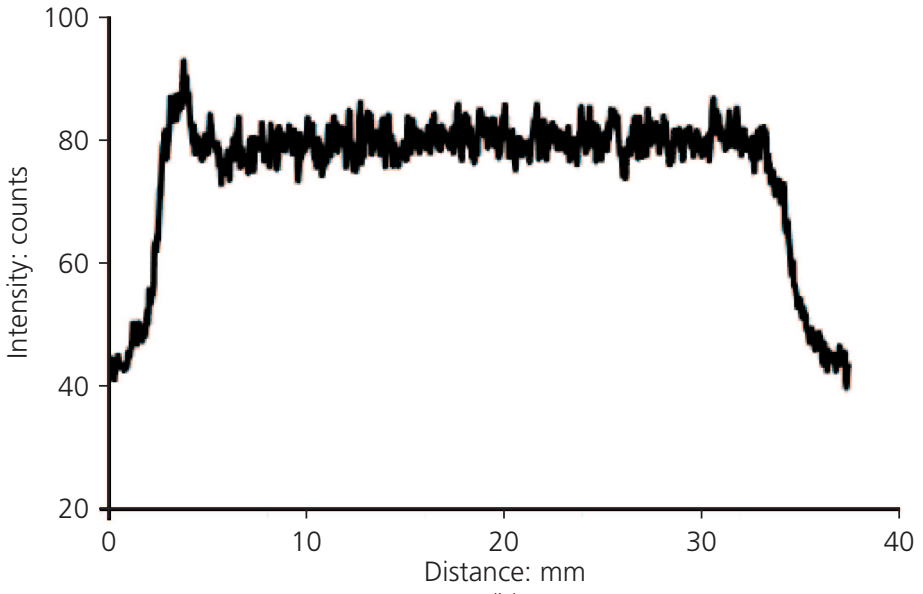

(b)

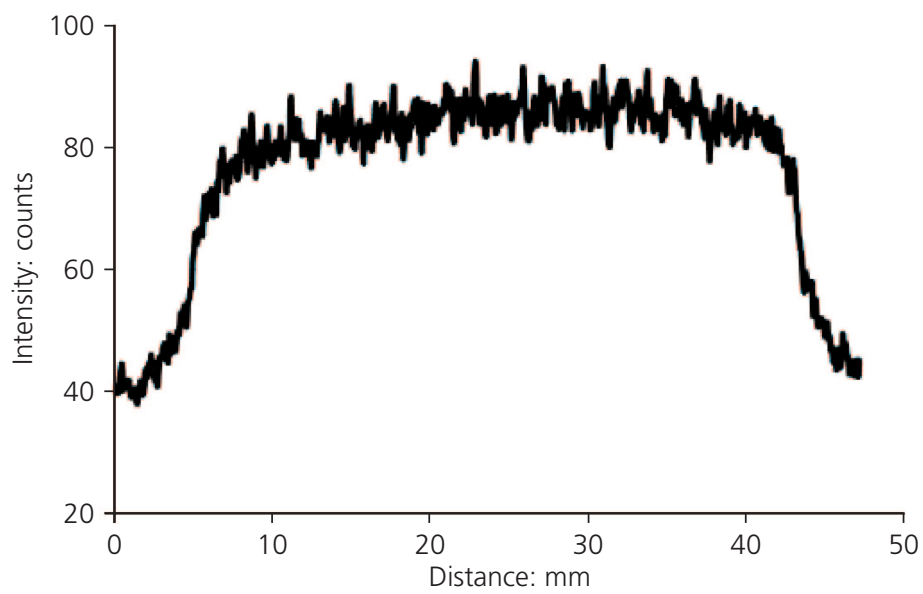

(d) ments are performed on cement with superplasticiser already present as part of the mix, rather than free in solution. In this case, uptake of nickel and europium by both BFS:OPC and PFA:OPC is almost complete $(>98 \%)$ and is not reversible. The absence of free 'ligand' precludes solubility enhancement but, equally, the superplasticiser ( $0 \cdot 5 \%$ ADVA Cast 551) is obviously not effective at blocking metal binding sites. Presumably, interactions between the superplasticiser and the cement during the early stages of hydration lead to the polymer becoming incorporated into cement hydration phases and, therefore, unavailable for subsequent interactions with the metals. Direct evidence that the first few seconds in the crystallisation of cement are crucial to its development has recently been obtained using in situ synchrotron X-ray diffraction (Schlegel et al., 2012).

Monoliths prepared with BFS:OPC and 0.5\% ADVA Cast 551 suffered from bleed; little or no bleed was found in samples prepared without superplasticiser or in samples of PFA:OPC. A similar observation was made by Morgan and Constable (2008) where much more bleed and segregation was observed in a 9:1 BFS:OPC cement than in a 3:1 PFA:OPC cement, both prepared with $0.3 \%$ and $0.8 \%$ ADVA Cast 551. They suggested that deflocculation of the cement particles had occurred owing to the presence of the superplasticiser, resulting in greater packing density of the powders on curing.

Whatever the cause, a significant proportion of the original metal inventory was found in the BFS:OPC bleed water after $48 \mathrm{~h}$, varying from $19 \%$ in the case of nickel to $32 \%$ for uranium. Autoradiography of the monoliths showed accumulation of uranium and thorium in the region adjacent to, and in contact with, the bleed water. Therefore, the metal inventory had not been dispersed effectively or incorporated homogeneously into the cement. Whether the presence of ADVA Cast itself is inhibiting metal encapsulation is unclear, although it is noted that bleed water that does not contain superplasticiser is also not 

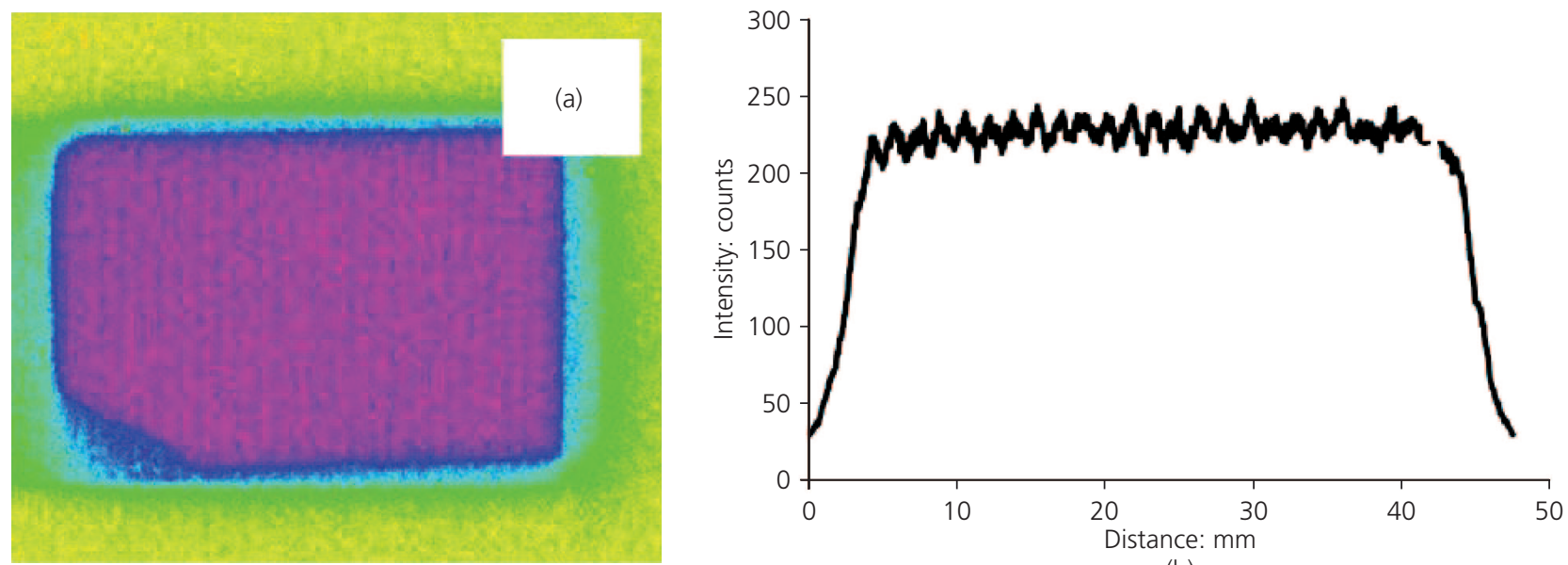

(b)
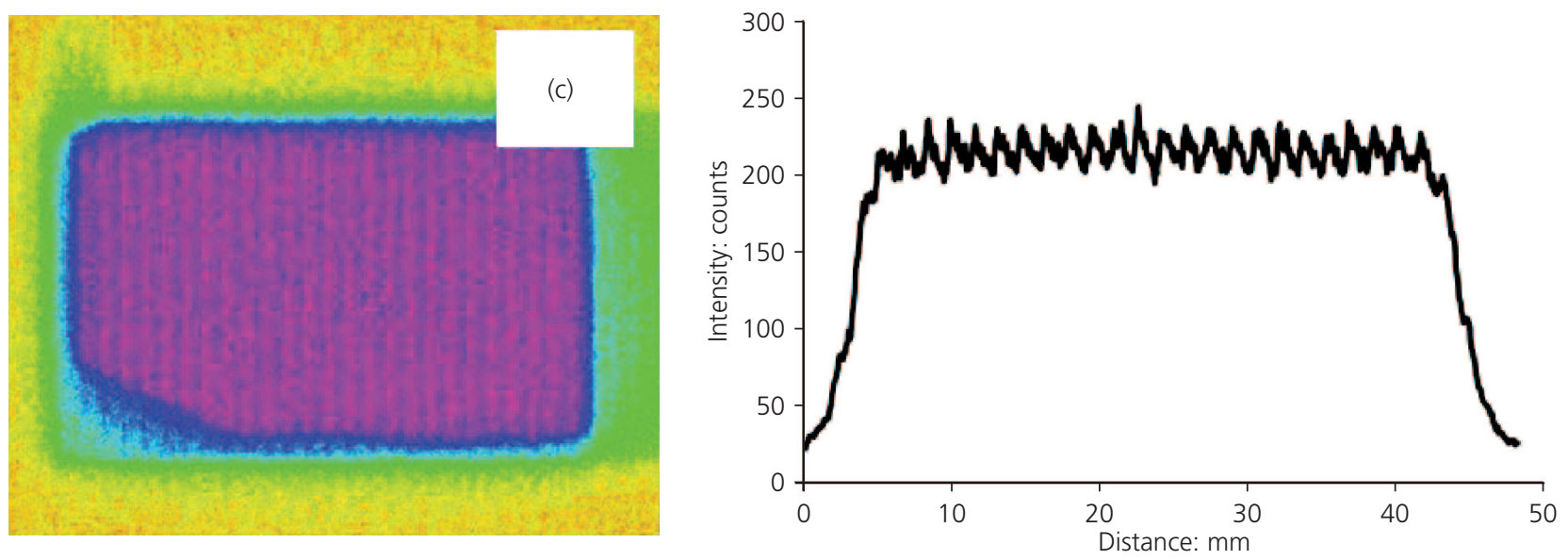

(d)

Figure 8. Autoradiographic image and profile plot of PFA:OPC cement containing uranium prepared (a), (b) with and (c), (d) without $0.5 \%$ ADVA Cast 551

enriched in the radionuclides. This implies that the behaviour observed is not simply an indirect consequence of superplasticiser-induced bleed.

The effectiveness of superplasticisers in dispersing colloidal cement phases has been ascribed to early attachment of the polymer to calcium aluminate $\left(\mathrm{C}_{3} \mathrm{~A}\right)$, which hinders attachment of sulfate ions to form ettringite (Plank et al., 2009). Over time, the superplasticiser is replaced by sulfate $\left(\mathrm{SO}_{4}{ }^{2-}\right)$ and the cement gains in strength. Compositional differences between the BFS and PFA must have a bearing on this process, in the case of the former causing bleed and mobilisation of normally insoluble metals. It is possible that the higher sulfur content of slag reduces or retards initial uptake of the superplasticiser by calcium aluminate, leaving it free to bind to the metal. As shown above, when available in solution, ADVA Cast is highly effective at both limiting metal uptake and releasing metals back to solution.
On longer timescales, the only metal to leach in appreciable concentrations from the cement monoliths was nickel. Even here, less than $0.005 \%$ of the original inventory was detected in the leachate.

The results of this research confirm the findings of earlier work on superplasticiser-modified cements, specifically their ability to bind and retain metal species. The metals studied encompass a range of oxidation states from nickel (II), through europium (III) and thorium (IV) to uranium (VI). Uranium, under oxidising conditions and in hexavalent form, is a relatively soluble element, although less so at high $\mathrm{pH}$. Thorium, in contrast, exists only in the tetravalent state and is extremely insoluble across most of the $\mathrm{pH}$ range. Its apparent mobility here is of potentially great significance as it may indicate similar behaviour by other tetravalent actinide species, notably plutonium (IV) and neptunium (IV). 

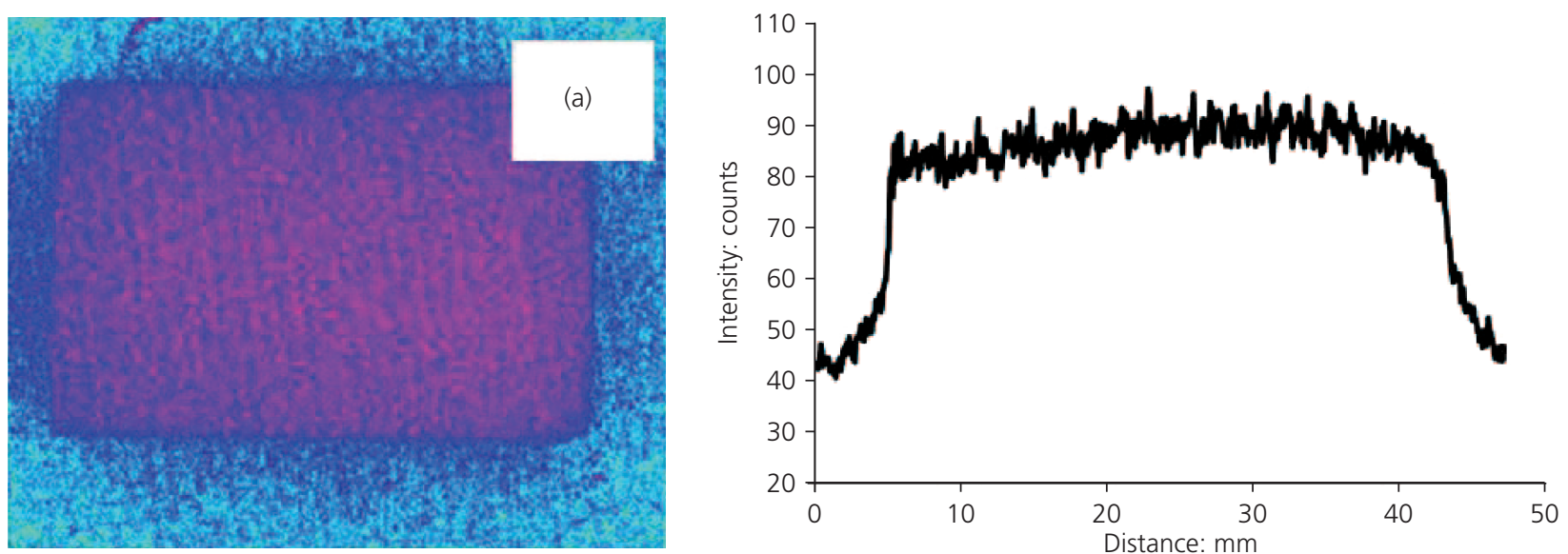

(b)
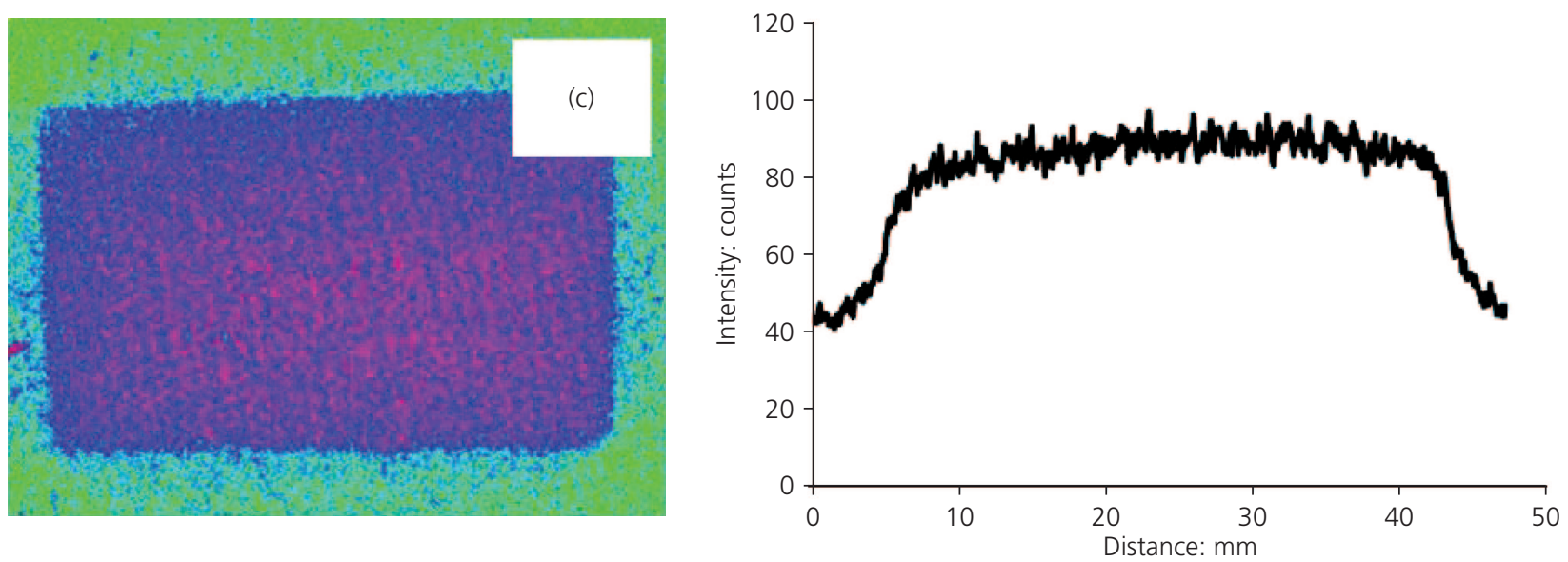

(d)

Figure 9. Autoradiographic image and profile plot of PFA:OPC cement containing thorium prepared (a), (b) with and (c), (d) without 0.5\% ADVA Cast 551

\section{Acknowledgements}

The authors would like to thank the Engineering and Physical Sciences Research Council Diamond Consortium and the Nuclear Decommissioning Authority (NDA) for funding this research. Special thanks are given to Drs Steve Williams of the NDA, Sneh Jain, Monica Felipe-Sotelo and Mr John Hinchliff for their technical support, advice and encouragement. AEM publishes with the permission of the Executive Director of the British Geological Survey, NERC.

\section{REFERENCES}

Aldridge S (2005) Some Aspects of Near Field Chemistry in a Nuclear Waste Repository. $\mathrm{PhD}$ thesis, Loughborough University, Loughborough, UK.

Amemiya $Y$ and Miyahara J (1988) Imaging plate illuminates many fields. Nature 336(November): 89-90.

Cetiner ZS (2007) Initial assessment of hydrous thorium(IV) solubility and speciation in geological environments: An experimental approach in presence of organic ligands. Asian Journal of Chemistry 19: 3228-3238.

Conner JR (1990) Chemical Fixation and Solidification of Hazardous Wastes. Van Nostrand Reinhold, USA.

Felmy A and Qafoku O (2004) An aqueous thermodynamic model for the complexation of nickel with EDTA valid to high base concentration. Journal of Solution Chemistry 33(9): 1161-1180.

Glasser FP (2001) Mineralogical aspects of cement in radioactive waste disposal. Mineralogical Magazine 65(5): 621-633.

Gonzalez AL, Li H, Mitch M, Tolk N and Duggan DM (2002)

Energy response of an imaging plate exposed to standard beta sources. Applied Radiation and Isotopes 57: 875-882.

Greenfield B, llett D, Ito M et al. (1998) The effect of cement additives on radionuclide solubilities. Radiochimica Acta 82: $27-32$.

Hewlett PC (ed.) (1998) Lea's Chemistry of Cement and Concrete, 4th edn. John Wiley, New York, USA. 
McCrohon R and Williams SJ (1997) Effect of Sikament 10 Superplasticiser on Radionuclide Solubility: UK Nirex Ltd, Didcot, Oxfordshire, UK, report.

Morgan S and Constable M (2008) Superplasticiser Irradiation Trials: Preparation and Evaluation Testing of Grout Samples Containing ADVA Cast 551. Magnox Electric Ltd (North), UK, report 4510177929 (14-2007/08N additional task), Waste Management Technology.

Petit J, Wirquin E and Dutoit B (2005) Influence of temperature on yield value of highly flowable micromortars made with sulfonate-based superplasticizers. Cement and Concrete Research 35: 256-266.

Plank J, Schroefl C, Gruber M, Lesti M and Sieber R (2009) Effectiveness of polycarboxylate superplasticizers in ultrahigh strength concrete: The importance of PCE compatibility with silica fume. Journal of Advanced Concrete Technology 7(1): $5-12$.

Pöyry Energy (2011) The 2010 UK Radioactive Waste Inventory. Department of Energy and Climate Change (DECC) and the Nuclear Decommissioning Authority (NDA), UK, report URN 10D/987 NDA/ST/STY(11)006.

Ramachandran VS (ed.) (1995) Concrete Admixtures Handbook, 2nd edn. Noyes Publications, New Jersey, USA.

Schlegel M, Pointeau I, Coreau N and Reiller P (2004) Mechanism of europium retention by calcium silicate hydrates: An EXAFS study RID G-4731-2010.
Environmental Science and Technology 38(16): $4423-$ 4431.

Schlegel M, Sarfraz A, Müller U, Panne U and Emmerling F (2012) First seconds in a building's life. In situ synchrotron X-ray diffraction study of cement hydration on the millisecond timescale. Angewandte Chemie International Edition 51(20): 4993-4996.

Shannon R (1976) Revised effective ionic radii and systematic studies of interatomic distances in halides and chalcogenides. Acta Crystallographica Section A 32: 751-767.

Takahashi S, Sakai E and Sugiyama T (2007) Study on leaching of hexavalent chromium from hardened concretes using tank leaching test. Journal of Advanced Concrete Technology 5(2): 201.

Warwick P, Evans N and Lewis T (2008) Effect of 'as disposed' complexants on the solubility of nickel (II), thorium (IV) and uranium (VI). Nuclear Decommissioning Authority, Cumbria, UK, NDA report NR3256A.

Yamada K, Takahashi T, Hanehara S and Matsuhisa M (2000) Effects of the chemical structure on the properties of polycarboxylate-type superplasticizer. Cement and Concrete Research 30(2): 197-207.

Zeissler CJ (1997) Comparison of semiconductor pixel array, phosphor plate and track-etch detectors for alpha autoradiography. Nuclear Instruments and Methods in Physics Research A392(1-3): 249-253.

\section{WHAT DO YOU THINK?}

To discuss this paper, please submit up to 500 words to the editor at www.editorialmanager.com/acr by 1 April 2013. Your contribution will be forwarded to the author(s) for a reply and, if considered appropriate by the editorial panel, will be published as a discussion in a future issue of the journal. 